\title{
ZETA POTENTIAL AND COAGULATION OF ZnO IN ALCOHOLS
}

\author{
E.H.P. LOGTENBERG* and H.N. STEIN \\ Laboratory of Colloid Chemistry, Eindhoven University of Technology, P.O. Box 513, \\ $5600 \mathrm{MB}$ Eindhoven (The Netherlands)
}

(Received 7 May 1985; accepted in final form 30 September 1985)

\section{ABSTRACT}

The zeta potential of $\mathrm{ZnO}$ dispersed in methanol is not influenced by the water content (up to $375 \mu \mathrm{l}$ per $100 \mathrm{ml}$ ), whereas it is shifted from negative to positive values for dispersions in ethanol or propanol.

Addition of $\mathrm{HCl}$ or $\mathrm{KOH}$ influences the zeta potential in a rather complex way: small amounts of $\mathrm{HCl}$ cause a shift to more positive values and small amounts of $\mathrm{KOH}$ to more negative values but, on this effect, the result of counter-ion adsorption is superimposed which predominates at large concentrations.

No distinct viscosity or specific solvent effects on the coagulation rate have been observed, and the results are consistent with electrostatic repulsion.

\section{INTRODUCTION}

Dispersions of inorganic solids in non-aqueous media are frequently surprisingly stable [1]. With this stability, three effects are of primary interest:

(i) The influence of the water content owing to the frequent contamination of non-aqueous media by water. In addition, any water present may be assumed to interact strongly with polar inorganic solids.

(ii) The effects of acid or alkali hydroxides due to the special role played by $\mathrm{H}^{+}$and $\mathrm{OH}^{-}$ions as potential determining ions for oxides in aqueous dispersions.

(iii) Specific solvent effects, which might influence the stability due to the particular solvent structure near an interface.

Effect (i) was studied by Romo [2] for dispersions of $\alpha-\mathrm{Al}_{2} \mathrm{O}_{3}$ and $\mathrm{Al}(\mathrm{OH})_{3}$ in aliphatic alcohols. An increase of the water content was found to lead to decreasing stability for $\alpha-\mathrm{Al}_{2} \mathrm{O}_{3}$ dispersions, and to increasing stability for $\mathrm{Al}(\mathrm{OH})_{3}$ dispersions. These effects were related to the influence of the water content on the zeta potential; increasing water content leads to a shift to more positive values which resulted in a charge reversal for $\alpha-\mathrm{Al}_{2} \mathrm{O}_{3}$ (which is negative in pure alcohols). Similar data about the influence of water on the zeta potential have been reported for rutile by Griot [3] and

\footnotetext{
*Present address: Houtinstituut TNO, Delft, The Netherlands.
} 
Jackson and Parfitt [4]; they might explain the findings of Chessick et al. [5] that aerosil dispersions in organic media can be destabilized by traces of water which are not sufficient to produce an adsorbed monolayer. The influence of storage time on the zeta potential of rutile in n-heptanol was taken as an indication of water adsorption from heptanol [6].

With regard to effect (ii), Jackson and Parfitt [4] summed up the general opinion that the surface charge on the solid is associated with an acid--base equilibrium between surface and alcohol, the resulting charge being determined by the concentration of solvated protons in the liquid phase. What remains to be investigated is to what extent this is modified by chemisorption of other ions.

Effect (iii) was reported in 1966 by Overbeek [7] to be an open question. More recently, Ninham [8] revived the idea that special solvent structure effects are important on the basis of direct measurements of repulsive forces between mica surfaces.

We thought it worthwhile to investigate dispersions of $\mathrm{ZnO}$ in organic media. Much of the previous work has been carried out with $\mathrm{TiO}_{2}$ as the solid; the properties of $\mathrm{ZnO}$ dispersions might reflect adsorption effects specific for the solid concerned.

\section{EXPERIMENTAL}

\section{Materials}

Zincoxide: ex Merck "pro analysi", ignited under a flow of oxygen for $4 \mathrm{~h}$ at $450^{\circ} \mathrm{C}$. For characterization of this solid, see Refs $[9,10]$. It is indicated, in accordance with the nomenclature in Ref. [10], by $\mathrm{ZnO} / \mathrm{O}_{2}$.

Methanol: ex Merck "pro analysi", purified by flushing through a 1-m column containing $500 \mathrm{~g}$ dried molsieve $3 \AA$ (Merck cat. number 5704). For every litre of alcohol, a fresh column was prepared by heating at $400^{\circ} \mathrm{C}$ under a flow of dried nitrogen for $24 \mathrm{~h}$. The dried methanol was flushed dropwise through a column containing $100 \mathrm{~g} \mathrm{ZnO} / \mathrm{O}_{2}$; directly afterwards the methanol was used for the preparation of dispersions. The water content of the resulting methanol was $15 \mu \mathrm{l}$ per $100 \mathrm{ml}$.

Ethanol: ex Merck "pro analysi", purified as described for methanol.

Propanol: ex Riedel de Haen "pro analysi", purified as described for methanol.

Potassium hydroxide: ex Merck "pro analysi", dissolved in dried ethanol or methanol to a $0.001 \mathrm{M}$ solution.

Hydrogen chloride: Merck "pro analysi" hydrochloric acid was diluted with dried alcohol to a $0.001 \mathrm{M}$ solution.

\section{Preparation of the dispersions}

Straight from the ignition tube, $0.4 \mathrm{~g} \mathrm{ZnO} / \mathrm{O}_{2}$ was added to $100 \mathrm{ml}$ dried alcohol. From this dispersion, $3.2 \mathrm{ml}$ was added to the alcohol (+ electrolyte 
or water). The total volume of the dispersion was then made up to $100.0 \mathrm{mI}$ with dried alcohol. Preparation and storage of the dispersions was carried out in a glove box freed from moisture; storage did not lead to an increase in the water content for the longest storage period in the present investigation (1.5 weeks).

\section{Methods}

Determination of the water content was performed by a Hewlett-Packard $5710 \mathrm{~A}$ gas chromatograph, using a $50 \mathrm{~cm} \times 1 / 8$ inch column with Porapack Q 150-200 mesh. The sensitivity of the detector was $1 \mu l \mathrm{H}_{2} \mathrm{O}$ per $100 \mathrm{ml}$ alcohol.

The concentration of $\mathrm{Zn}^{2+}$ ions was determined by the differential pulse anodic stripping method [11]. The alcoholic $\mathrm{ZnO}$ dispersion was centrifuged; $10 \mathrm{ml}$ supernatant was transferred to a $50-\mathrm{ml}$ calibrated flask, and the alcohol was evaporated under reduced pressure at $50^{\circ} \mathrm{C}$. The residue was treated by addition of $50.0 \mathrm{ml} 0.1 \mathrm{M}$ solution (in the case of $\mathrm{HCl} / \mathrm{KCl}$ solutions: $0.1 M$ in $\mathrm{Cl}^{-}$; in the case of $\mathrm{KCl} / \mathrm{KOH}$ solutions: $0.1 M$ in $\mathrm{K}^{+}$), and ultrasonication for $30 \mathrm{~min}$ at $50^{\circ} \mathrm{C}$.

Zeta potentials were determined by electrophoresis in a Rank Brothers Mark II micro-electrophoresis apparatus, with a grease-free flat cell. The criteria for correct measurement of mobilities in non-aqueous media given by van der Minne and Hermanie [12] were obeyed. The zeta potentials were calculated from the mobilities by means of the Hückel equation [13].

Coagulation rates were determined in a stirred cylindrical vessel using a stirring speed of $700 \mathrm{rpm}[9,14]$.

\section{RESULTS AND DISCUSSION}

\section{The influence of the water content}

Figure 1 shows the influence of increasing water content on the zeta potential. For propanol, the same trend is observed as reported by Romo [2] for $\alpha-\mathrm{Al}_{2} \mathrm{O}_{3}$ : a shift of the negative zeta potential found in water-free propanol, in the positive direction leads to a charge reversal. Ethanol also shows a transition from a negative to a positive zeta potential with increasing water content, but in methanol no influence of water on the zeta potential is apparent, up to $350 \mu \mathrm{l} \mathrm{H} \mathrm{H}_{2} \mathrm{O}$ per $100 \mathrm{ml}$.

The data presented in Fig. 1 show considerable spread; this is considered to be due to the low values (in absolute sense) of the electrophoretic mobilities in the non-aqueous media, and to the spread in the particle size. In this respect comparison with the results of other investigators $[2,6]$ is not possible since in the papers concerned only average values of zeta potentials are mentioned.

In the interpretation of these data, two alternatives can be ruled out: adsorption of water at the $\mathrm{ZnO} /$ alcohol interface, and a change of $\mathrm{Zn}^{2+}$ 


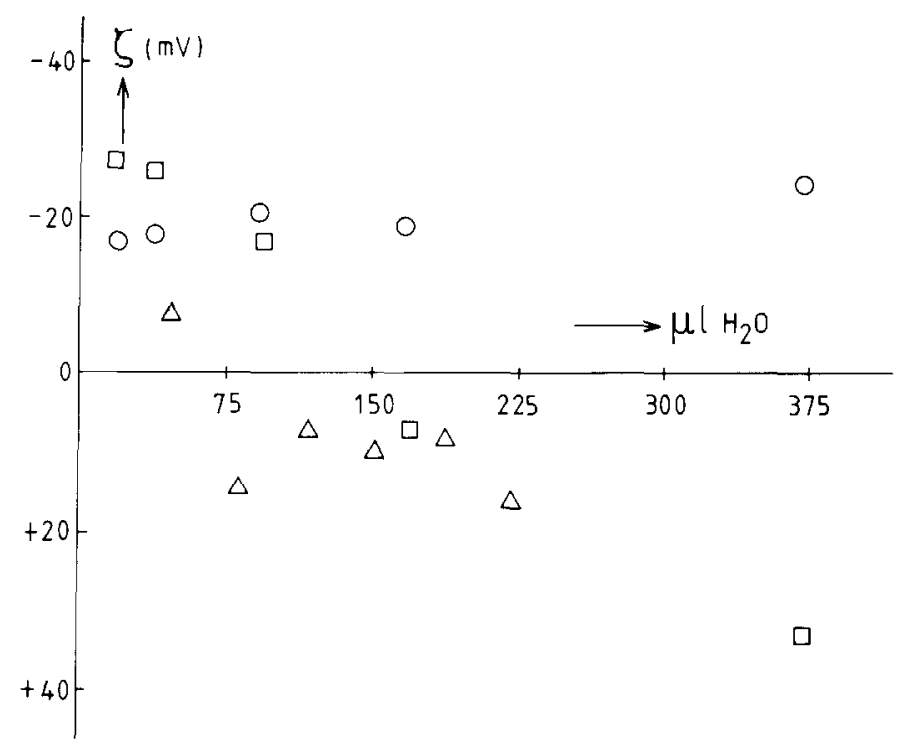

Fig. 1. Zeta potential as a function of the water content $(\mu \mathrm{l}$ per $100 \mathrm{ml})$. (O), Methanol; $(\square)$, ethanol; $(\triangle)$, propanol.

concentration in the medium caused by the presence of water. The former alternative is exluded, because analysis of the alcohols before and after passage of the second column (filled with $\mathrm{ZnO} / \mathrm{O}_{2}$; see Experimental) showed that, during this passage, the water content of the alcohol did not decrease. This had already been observed with the first alcohol drops passing through the column. Thus, in spite of Morimoto and co-workers' finding $[15,16]$ that water is adsorbed by $\mathrm{ZnO}$ preferentially to alcohols from the gas phase, under the conditions of our experiments no water adsorption took place. Neither does an increasing water content lead to increased $\mathrm{Zn}^{2+}$ concentrations: the latter remains of the order of $5 \cdot 10^{-5} \mathrm{~mol} \mathrm{l}^{-1}$ throughout in methanol, and $1-3 \cdot 10^{-5} \mathrm{~mol} \mathrm{l}^{-1}$ in ethanol.

In contrast with the data reported by Micale et al. for rutile in heptanol [6], no effect of time was found up to 3 days. Statistical analysis by the method of paired comparisons [17] showed no significant difference on the 0.05 confidence limit between results obtained after 1 day and after 3 days.

A possible explanation of the data is that water is dissociated to a larger extent than the alcohols and that, consequently, an increased water content leads to increased $\mathrm{H}^{+}$and $\mathrm{OH}^{-}$concentrations, while $\mathrm{H}^{+}$ions are preferentially adsorbed by the $\mathrm{ZnO} / \mathrm{O}_{2}$. Since the degree of dissociation of the alcohols themselves decreases with increasing chain length [18], a larger effect in the higher alcohols is expected.

Figure 2 presents the relation between the zeta potential and the rate of coagulation. In this figure, the averaged curve for $\mathrm{ZnO} / \mathrm{O}_{2}$ in water $[9,10]$ 
is also drawn. No distinct difference between data pertaining to different alcohols can be detected, in spite of the differences in their viscosities $\left(\eta_{\text {propanol }}: \eta_{\text {methanol }}\left(\right.\right.$ at $\left.\left.20^{\circ} \mathrm{C}\right)=3.78\right)$; and it is very doubtful whether the difference between the coagulation rates in water and in the alcohols near $\zeta=0$, is significant, in view of the spread of the data. This spread is considered to be caused by both the uncertainty in the zeta potential and the difficulty of reproducing exactly the flow field in the apparatus concerned.

Apparently, the viscosity influences the coagulation at a given average shear rate only to a minor extent (cf. the use of the parameter $A /\left(36 \pi \eta_{0} a^{3} \dot{\gamma}\right)$ in present-day theory on pair formation of spherical particles in a shear field [19]; $A$ = the Hamaker constant, $\eta_{0}=$ the viscosity of the medium, $a=$ the particle radius, $\gamma=$ the shear rate).

Figure 2 also shows that there is no clear influence of a specific medium structure near the interface on the coagulation rate.

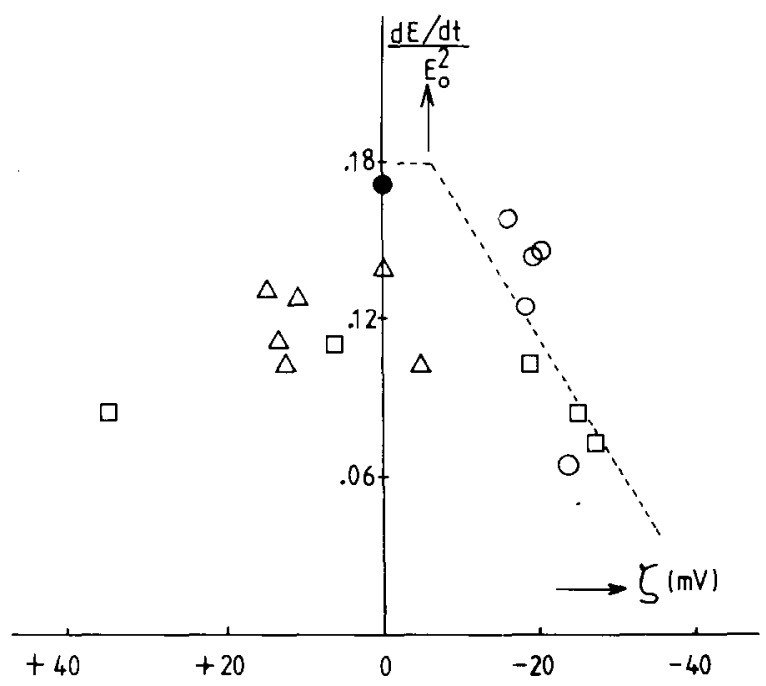

Fig. 2. Rate of coagulation as a function of zeta potential. $E=$ light extinction; $t=$ time; $E_{0}=$ light extinction at $t=0$. Symbols as in Fig. 1. Dotted line: Results of $\mathrm{ZnO} / \mathrm{O}_{2}$ in aqueous $\mathrm{KCl}$ solutions.

\section{Influence of acidity}

The zeta potentials are distinctly influenced by changes in acidity (Fig. 3). At low concentrations of added $\mathrm{HCl}$ or $\mathrm{KOH}$, the zeta potential follows the expected trend of shift to more positive values in increasingly acid (or decreasingly alkaline) media. However, at larger concentrations the potential curve is bent in the opposite direction.

This indicates adsorption of $\mathrm{Cl}^{-}$ions, which is stimulated by the presence of adsorbed $\mathrm{H}^{+}$ions, and adsorption of $\mathrm{K}^{+}$ions, which is stimulated by ad- 
sorbed $\mathrm{OH}^{-}$ions (or formation of $\mathrm{ZnO}^{-}$groups on the $\mathrm{ZnO}$ surface by dissociation of $\mathrm{ZnOH}$ groups). Both $\mathrm{Cl}^{-}$and $\mathrm{K}^{+}$ions are chemisorbed, but this chemisorption is enhanced by adsorbed $\mathrm{H}^{+}$and $\mathrm{OH}^{-}$ions, respectively: near a surface $\mathrm{ZnOH}_{2}^{+}$group, $\mathrm{Cl}^{-}$ions can be adsorbed in superequivalent amount. The zeta potential then decreases with increasing [HCl], because it is associated with the average potential in the electrokinetic slipping plane (and associated with the net charge behind this plane), while the adsorption is determined by the local potential at adsorption sites. Similar remarks can be made about $\mathrm{K}^{+}$ions being adsorbed near $\mathrm{ZnO}^{-}$groups on the $\mathrm{ZnO}$ surface.

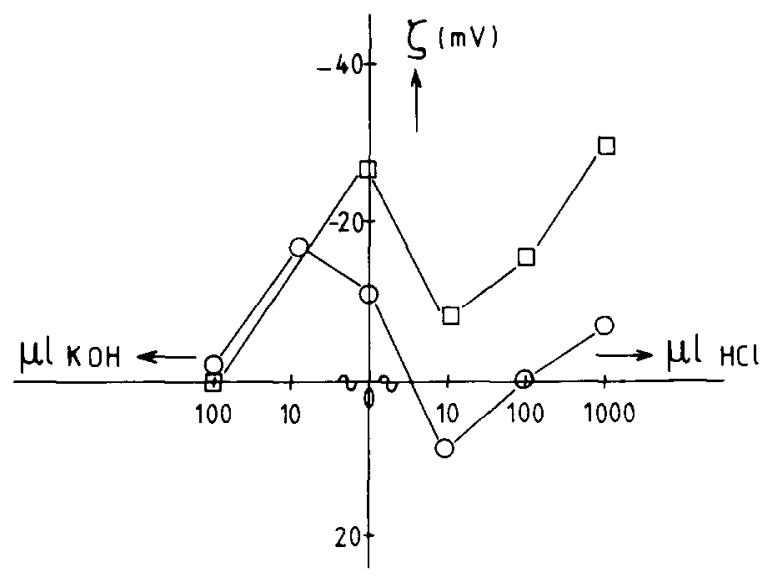

Fig. 3. Zeta potential of $\mathrm{ZnO}$ as a function of acidity $(\mu 1$ per $100 \mathrm{ml})$. (O), Methanol; (), ethanol.

For $\mathrm{ZnO}$ dispersed in aqueous solutions, analogous effects have only been found for anions $[10,20]$. It appears from the data presented in this work that, in alcohols, stimulated adsorption of both cations and anions occurs.

The coagulation rate, when plotted against the zeta potential, shows similar trends in the alcohols and water (Fig. 4). Thus, again significant effects of both the viscosity and specific molecular configurations of the media near the interface are excluded.

Our conclusion is that the influences of increasing water content and acidity on the coagulation rate of $\mathrm{ZnO}$ in methanol, ethanol or propanol are consistent with a purely electrostatic repulsion.

\section{SUMMARY}

Addition of water effects a shift of the zeta potential of $\mathrm{ZnO}$ to more positive values in ethanol and propanol, but not in methanol. This is explained by preferential adsorption of $\mathrm{H}^{+}$from the higher alcohols.

Addition of $\mathrm{HCl}$ effects a shift of the zeta potential to more positive 


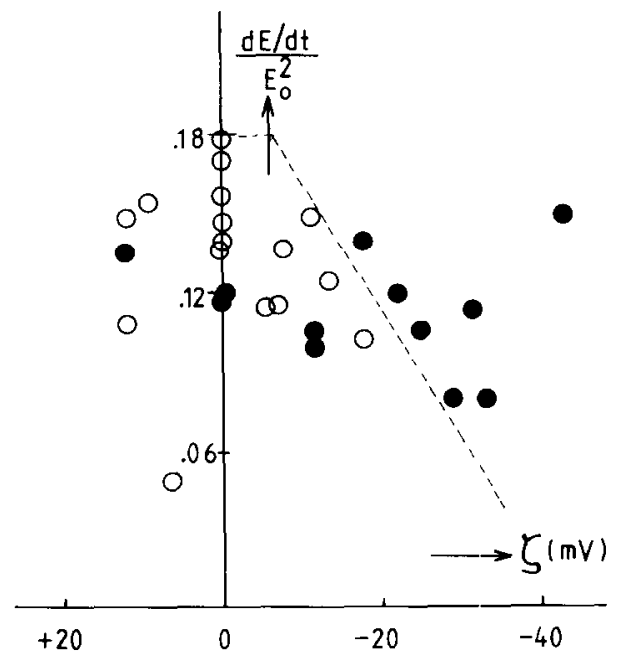

Fig. 4. Rate of coagulation as a function of zeta potential in dispersions with varying acidity. (O), Methanol; (•), ethanol.

values, while addition of $\mathrm{KOH}$ results in a similar shift to more negative values. At larger concentrations of acid or alkali, the trends are reversed, indicating stimulated adsorption of counter-ions.

A plot of the coagulation rate versus the zeta potential in alcohols is similar to that observed in water.

\section{ACKNOWLEDGEMENT}

The authors wish to thank A.J. Kuin for assistance in carrying out the experiments.

\section{REFERENCES}

1 J. Lyklema, Adv. Colloid Interface Sci., 2 (1968) 65.

2 L.A. Romo, Discuss. Faraday Soc., 42 (1966) 322.

3 O. Griot, Trans. Faraday Soc., 62 (1966) 2904.

4 P. Jackson and G.D. Parfitt, Kolloid Z. Z. Polym., 244 (1971) 240.

5 J.J. Chessick, A.C. Zettlemoyer and G.J. Young, J. Colloid Sci., 13 (1958) 372.

6 F.J. Micale, Y.K. Lui and A.C. Zettlemoyer, Discuss. Faraday Soc., 62 (1966) 238.

7 J.Th.G. Overbeek, Discuss. Faraday Soc., 42 (1966) 7.

8 B.W. Ninham, d. Phys. Chem., 84 (1980) 1423.

9 E.H.P. Logtenberg, The Relation between the Solid State Properties and the Colloid Chemical Behaviour of Zinc Oxide, Ph.D. Thesis, Eindhoven, 1983.

10 E.H.P. Logtenberg and H.N. Stein, to be published.

11 A.M. Bond, Modern Polarographic Methods in Analytical Chemistry, Marcel Dekker, New York, NY, 1980. 
12 J.L. van der Minne and P.H. Hermanie, J. Colloid Sci., 7 (1952) 600.

13 J.Th.G Overbeek, in H.R. Kruyt (Ed.), Colloid Science, Vol. I, Elsevier, Amsterdam, 1952 , p. 208.

14 E.H.P. Logtenberg and H.N. Stein, J. Colloid Interface Sci., 104 (1985) 258.

15 T. Morimoto, M. Kiriki and M. Nagao, J. Phys. Chem., 84 (1980) 2058.

16 M. Nagao and T. Morimoto, J. Phys. Chem., 84 (1980) 2054.

17 H.A. David, The Method of Paired Comparisons, Griffin, New York, NY, 1963.

18 B.E. Conway, Proton Solvation and Proton Transfer Processes in Solution. in J.O'M. Bockris (Ed.), Modern Aspects of Electrochemistry, Vol. III, Butterworth, 1964, Ch. 2.

19 T.G.M. van de Ven and S.G. Mason, Colloid Polymer Sci., 255 (1977) 468.

20 H.F.A. Trimbos and H.N. Stein, J. Colloid Interface Sci., 77 (1980) 386. 